\title{
Urinary Tract Infections in the First 6 Months after Renal Transplantation
}

\author{
Ziad Arabi $\mathbb{D}^{1},{ }^{1,2,3}$ Khalefa Al Thiab, ${ }^{2,4}$ Abdulrahman Altheaby $\mathbb{D}^{\mathbb{D}},{ }^{1,2,3}$ Ghaleb Aboalsamh, ${ }^{2,3,5}$ \\ Samy Kashkoush, ${ }^{2,3,5}$ Mohamad Almarastani, ${ }^{2,3,5}$ Mohammed F. Shaheen, ${ }^{2,3,5}$ \\ Abdulrahman Altamimi, ${ }^{2,3,5}$ Wael O'hali $\mathbb{D}^{2,3,5}$ Khalid Bin Saad, ${ }^{2,3,5}$ Lina Alnajjar, \\ Rawan Alhussein $\left(\mathbb{D},{ }^{7}\right.$ Raghad Almuhiteb $\mathbb{D},{ }^{7}$ Bashayr Alqahtani $\left(\mathbb{D},{ }^{7}\right.$ Rayana Alotaibi, ${ }^{7}$ \\ Marah Alqahtani, ${ }^{7}$ and Mohammed Tawhari ${ }^{10}{ }^{1,2,3}$ \\ ${ }^{1}$ Division of Adult Transplant Nephrology, King Abdulaziz Medical City, Riyadh, Saudi Arabia \\ ${ }^{2}$ King Abdullah International Medical Research Center, Riyadh, Saudi Arabia \\ ${ }^{3}$ College of Medicine, King Saud Bin Abdulaziz University for Health Sciences, Riyadh, Saudi Arabia \\ ${ }^{4}$ Pharmaceutical Care Department, King Abdulaziz Medical City, Riyadh, Saudi Arabia \\ ${ }^{5}$ Department of Hepatobiliary Sciences and the Organ Transplant Center, King Abdulaziz Medical City, Riyadh, Saudi Arabia \\ ${ }^{6}$ Department of Pharmacy Practice, College of Pharmacy, Princess Nourah Bint Abdulrahman University, Riyadh, Saudi Arabia \\ ${ }^{7}$ College of Pharmacy, Princess Nourah Bint Abdulrahman University, Riyadh, Saudi Arabia
}

Correspondence should be addressed to Ziad Arabi; ziadarabi@yahoo.com

Received 3 July 2021; Revised 4 September 2021; Accepted 30 September 2021; Published 15 November 2021

Academic Editor: Martin Sedlacek

Copyright (c) 2021 Ziad Arabi et al. This is an open access article distributed under the Creative Commons Attribution License, which permits unrestricted use, distribution, and reproduction in any medium, provided the original work is properly cited.

Purpose. Urinary tract infections (UTIs) are common in the first 6 months after renal transplantation, and there are only limited data about UTIs after transplantation in Saudi Arabia in general. Methods. A retrospective study from January 2017 to May 2020 with 6-month follow-up. Results. 279 renal transplant recipients were included. Mean age was $43.4 \pm 16.0$ years, and114 (40.9\%) were women. Urinary stents were inserted routinely during transplantation and were removed $35.3 \pm 28$ days postoperatively. Ninety-seven patients (35\%) developed urinary tract infections (UTIs) in the first six months after renal transplantation. Of those who developed the first episode of UTI, the recurrence rates were 57\%, 27\%, and $14 \%$ for having one, two, or three recurrences, respectively. Late urinary stent removals, defined as more than 21 days postoperatively, tended to have more UTIs (OR: 1.43, P: 0.259, CI: 0.76-2.66). Age >40, female gender, history of neurogenic bladder, and transplantation abroad were statistically significant factors associated with UTIs and recurrence. Diabetes, level of immunosuppression, deceased donor renal transplantation, pretransplant residual urine volume, or history of vesicoureteral reflux (VUR) was not associated with a higher incidence of UTIs. UTIs were asymptomatic in $60 \%$ but complicated with bacteremia in $6 \%$ of the cases. Multidrug resistant organisms (MDROs) were the causative organisms in $42 \%$ of cases, and in-hospital treatment was required in about $50 \%$ of cases. Norfloxacin + Bactrim DD $(160 / 800 \mathrm{mg})$ every other day was not associated with the lower risk of developing UTIs compared to the standard prophylaxis daily Bactrim SS (80/400 mg). Conclusion. UTIs and recurrence are common in the first 6 months after renal transplantation. Age $>40$, female gender, neurogenic bladder, and transplantation abroad are associated with the increased risk of UTIs and recurrence. MDROs are common causative organisms, and hospitalization is frequently required. Dual prophylactic antibiotics did not seem to be advantageous over the standard daily Bactrim. 


\section{Background}

Urinary tract infections (UTIs) are common among kidney transplant recipients in the first year after transplantation. The reported incidence varies from $11.7 \%$ to $67.5 \%$ based on the definition and the design of studies $[1,2]$. UTIs remain a leading cause of hospitalization after kidney transplantation [3].

Several risk factors were identified and are thought to increase the risk of UTIs after renal transplant. These include older age, female gender, diabetes, history of acute rejection [2], delayed graft function [4], deceased donor kidney transplantation, longer duration of dialysis [5], and urological abnormalities [3]. Timing of stent removal and the use of antibiotic prophylaxis are important modifying factors. In this study, we retrospectively review the data from our transplant center pertaining to the development of UTIs in the first 6 months after renal transplantation. There are only limited data about UTIs after transplantation in Saudi Arabia in general [6-8].

\section{Methods}

After obtaining the institutional board review approval (RC20/138/R), a retrospective study was conducted to review the charts of renal transplant recipients at King Abdulaziz Medical City, Riyadh, Saudi Arabia, from January 2017 to May 2020 with 6-month follow-up.

Demographic patients' data, comorbidities, and renal transplantation data were collected. Transplant outcomes and complications with specific focus on posttransplant UTIs were collected. These included the incidence, potential risk factors, symptomatology, prevalence of multidrug-resistant organisms (MDROs), need for hospitalization, and treatment.

We classified UTIs similar to the previous studies [9-11] according to their symptoms as follows:

(1) Asymptomatic bacteriuria: $>10^{5}$ colony-forming unit $(\mathrm{cfu}) / \mathrm{mL}$

(2) Simple (uncomplicated) UTI: positive urine culture in addition to any urinary symptoms such as dysuria, urgency, frequency, or suprapubic pain

(3) Complicated UTI: positive urine culture in addition to systemic symptoms such as fever, chills, and flank/ allograft pain

(4) Complicated UTI with bacteremia

(5) Recurrent UTI: more than one UTI in the first 6 months

2.1. Statistical Analysis. All analyses were performed using IBM SPSS software 23.0 (IBM Co., Armonk, NY, USA). Continuous variables were presented as means \pm standard deviation (SD). Categorical variables were expressed as numbers and percentages. We compared data using the $t$ test, Mann-Whitney $U$ test, chi-squared, or Fisher's exact tests as appropriate. Multivariable risk factor analysis was performed using logistic regression analysis. All statistical tests were two-sided, and $P$ values $<0.05$ were considered statistically significant.

\section{Results}

A total of 279 renal transplant recipients were included. The mean age was $43.4 \pm 16.0$ years; 114 (40.9\%) were women. Eighty percent of the participants received living donor transplant. Ninety-seven patients (35\%) developed UTI in their first six month after renal transplantation (Table 1).

The first UTI occurred in $40.8 \pm 44.5$ days from transplant. For those who developed first UTI, the recurrence rate was $57 \%, 27 \%$, and $14 \%$ for the first, second, and third recurrences occurring in $70.1 \pm 45.4,89.9 \pm 39.9$, and $124.2 \pm 44.5$ days from transplant, respectively (Table 2 ).

Most of the UTIs occurred in the first 2 months. Recurrence was mostly in the second month of transplant, and it decreased with time. UTIs were asymptomatic, simple, complicated, or complicated with bacteremia in 63.7\%, $14.4 \%, 12.4 \%$, or $6.2 \%$, respectively.

3.1. Factors. Age $>40$ (P: 0.012, OR: 2.176, CI: 1.187-3.986), being a female $(P<0.001$, OR: 5.008, CI: 2.74-9.156), receiving renal transplant abroad $(P<0.001$, OR: $5.008, \mathrm{CI}$ : 2.607-27.05), and being diagnosed with neurogenic bladder ( $P$ : 0.048, OR:5.646; CI:1.016-31.379) were important factors associated with UTIs and recurrences, whereas diabetes, the type of transplant (deceased donor versus living donor), pretransplant residual urine volume, and the presence of vesicoureteral reflux (VUR) were not associated with the higher incidence of UTIs. Similarly, urinary leak or ureteral stenosis was not associated with the increased incidence of UTIs. In addition, there was no association between the renal function (i.e., serum creatinine at 1 and 6 months after transplantation) and UTIs.

The level of immunosuppression (induction type, episodes of acute rejection, or detection of polyoma viremia) was not associated with the higher incidence of UTI.

In our study, the urinary stents were cystoscopically removed at a mean of $35.3 \pm 28$ days postoperatively. When the urinary stent was removed after 21 days, there was a trend towards a higher incidence of UTIs although it was not statistically significant (OR 1.43, P: 0.259, CI: 0.76-2.66). Of note, when stents were removed urgently (for non-UTI reasons such migrated or fallen stents), there were less UTIs.

Dual antibiotic prophylaxis (norfloxacin along with Bactrim DD) when compared to the standard prophylaxis with Bactrim SS daily alone was not associated with the decreased risk of UTIs (Table 3).

UTIs were asymptomatic in about $60 \%$ or complicated with bacteremia in $6 \%$ of the cases. Multidrug-resistance organisms (MDROs) were the causative organisms in $42 \%$ of cases. Inhospital treatment was required in about 50\% (Table 2).

\section{Discussion}

In our study, the incidence of UTIs in the first 6 months after renal transplantation was 35\%. Most of the UTIs occurred in the first 2 months, and recurrence was mostly in the second 

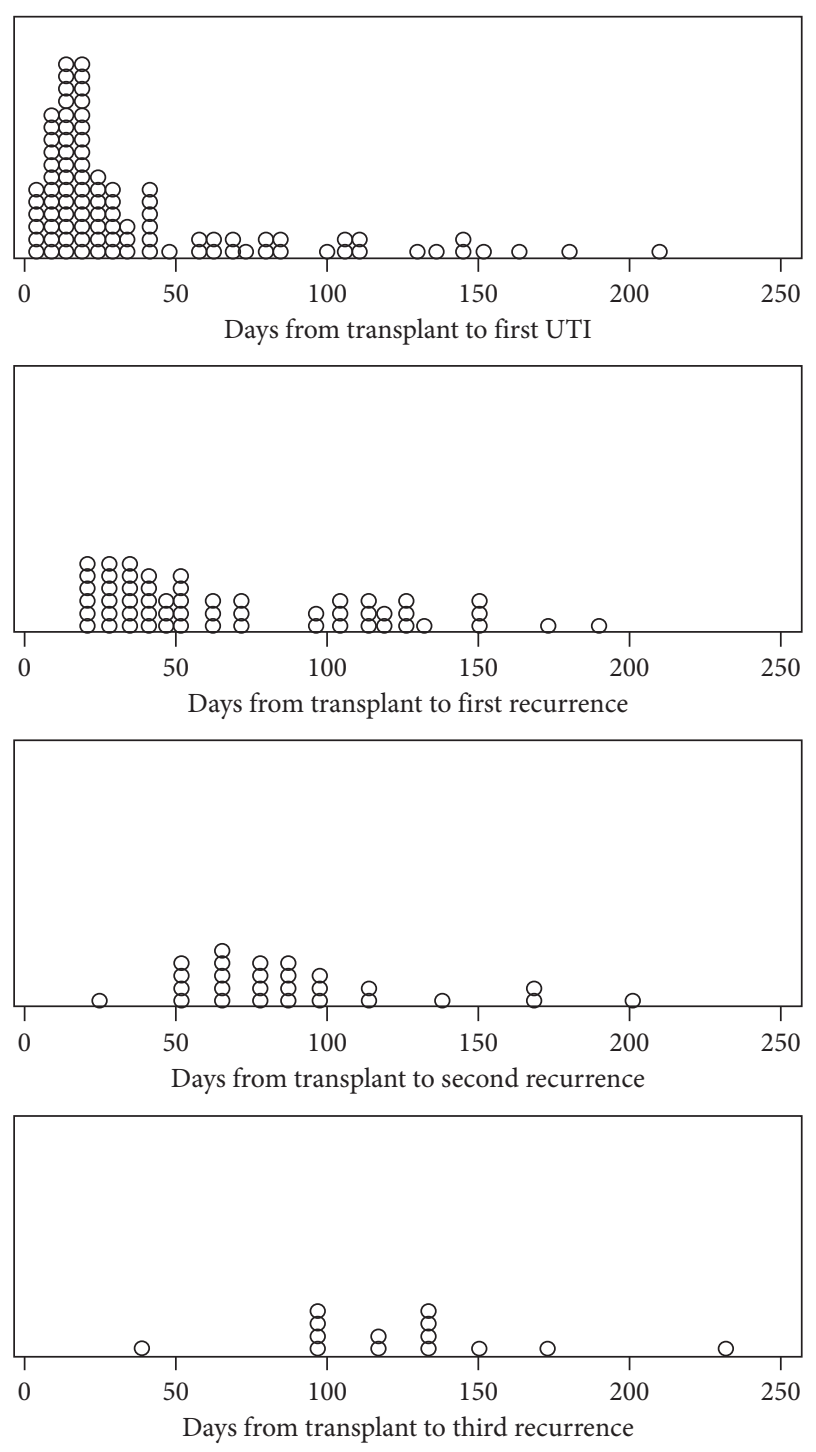

FIgURE 1: Timing of UTIs and recurrence.

month of transplant and it decreased with time. Figure 1 shows the timing of UTI and its recurrence. Although this incidence is high, it remains comparable and follows a similar course to what is reported in other studies $[1,2,9,12]$.

At our center, we stop routine screening with urine cultures beyond 6 months. This is due to the lack of evidence that treatment of asymptomatic UTIs has an impact on patient and graft outcomes including hospitalization $[13,14]$. That is true, especially if the urinary stent has already been removed.

In our study, age $>40$, female gender, transplantation abroad, and history of neurogenic bladder were identified as important factors of UTIs and recurrence, whereas diabetes and the type of transplant (deceased versus living donor) were not. These findings are in line with previously published studies [12, 15-19].

Urological abnormalities are important factors for UTIs after renal transplantation [3]. In our study, neurogenic bladder and intermittent urinary self-catherization but not the presence of vesicoureteral reflux (VUR) were associated with the higher incidence of UTIs. This may be due to the low number of people with VUR (2.5\%) and can also be related to the absence of the VUR in the transplanted kidney [20].

Our induction protocol consisted of basiliximab for lowimmunological-risk transplantation and thymoglobulin (rATG) for high-immunological-risk transplantation. We use the standard triple immunosuppression therapy (tacrolimus, mycophenolate, and prednisolone) [21]. The association between the type of induction agent and UTIs has not been consistent $[12,15]$. Our study does not show an association between the induction agent and post-renaltransplant UTIs. Our report also found no association between acute rejection and UTIs $[12,18]$.

No observed association was noted between the renal function after transplantation and the development of UTIs. This finding is in keeping with some previously published reports as well. For example, Papasotiriou et al. found no association between graft function and UTI [12]. Other researchers, however, found that the occurrence of complicated UTI has a negative impact on graft function [22].

Similarly, the incidence of urinary leak or ureteral obstruction after transplantation was low in our study and was not associated with a higher incidence of UTIs. Pretransplant residual urine volume was not a risk factor for UTI either.

Unlike our findings, some studies showed that diabetic nephropathy as a cause of ESRD is a risk factor for recurrent UTIs [23].

Shorter duration of effective therapy has been implicated as a risk factor for recurrent UTIs [23]. Our approach in regard to the duration of antibiotic treatment depends on the symptoms and complexity of the UTIs [24]. We treat asymptomatic UTI in the first 6 months after transplantation, especially if the urinary stent is still in place. We also treat simple UTIs for one week. However, we treat more complex UTIs (especially MDRO) for more prolonged durations (two weeks or at least one week plus subsequent suppressive antibiotic therapy such as nitrofurantoin or fosfomycin in the case of susceptible organism). Centers may follow slightly different recommendations for the management of UTI in kidney transplantation [25]. Patients who were transplanted abroad seemed to have a much higher risk for all complications including UTIs and recurrence of UTIs. This could be related to the difference in surgical techniques and standards of transplantation practices as this may happen under less-than-ideal precautions such as in the case of transplant tourism.

Ureteric stents may help to reduce early postoperative complications (leak and stricture) but increase the likelihood of UTI [26]. Infection while having a ureteric stent was associated with a high recurrence rate of UTI even after stent removal [27]. Studies have showed that earlier stent removal ( $<3$ weeks) may decrease the incidence of UTIs without increasing the incidence of urinary leakage [28].

Our center used to target removal of the stent in the first 8 weeks after living donor kidney transplantation and 12 weeks after deceased donor kidney transplantation. In 2018, our center modified its protocol for stent removal after renal transplantation to the following: 
TAble 1: Patients' characteristics.

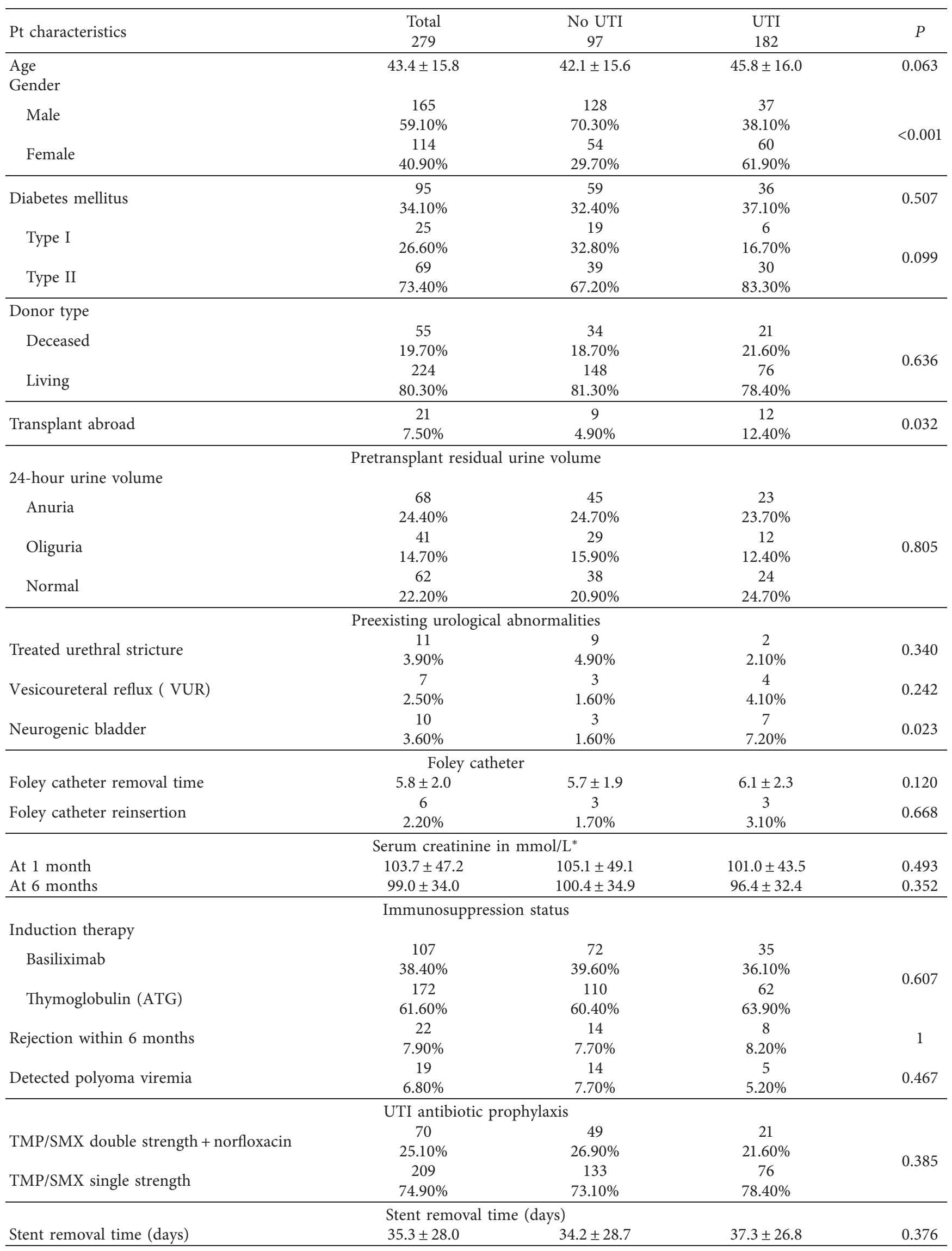


TABLE 1: Continued.

\begin{tabular}{|c|c|c|c|c|}
\hline Pt characteristics & $\begin{array}{c}\text { Total } \\
279 \\
\end{array}$ & $\begin{array}{c}\text { No UTI } \\
97\end{array}$ & $\begin{array}{l}\text { UTI } \\
182 \\
\end{array}$ & $P$ \\
\hline \multicolumn{5}{|c|}{ Urgent stent removal due to non-UTI reasons } \\
\hline Stent migration to urethra & $\begin{array}{c}6 \\
2.1 \%\end{array}$ & $\begin{array}{c}5 \\
1.8 \%\end{array}$ & $\begin{array}{c}1 \\
0.30 \%\end{array}$ & $<0.011$ \\
\hline \multicolumn{5}{|c|}{ Postrenal transplant surgical complications } \\
\hline Urine leak & $\begin{array}{c}3 \\
1.10 \%\end{array}$ & $\begin{array}{c}1 \\
0.50 \%\end{array}$ & $\begin{array}{c}2 \\
2.10 \%\end{array}$ & 0.554 \\
\hline Ureteral stenosis & $\begin{array}{c}6 \\
2.20 \%\end{array}$ & $\begin{array}{c}3 \\
1.60 \%\end{array}$ & $\begin{array}{c}3 \\
3.10 \%\end{array}$ & 0.668 \\
\hline
\end{tabular}

Continuous data were reported as $(\text { mean } \pm \mathrm{SD})^{*}$, and categorical data were reported as numbers and percentages. ${ }^{\dagger}$ Detected polyoma viremia $>50$ copies $/ \mathrm{ml}$.

TABLE 2: Timing and symptomatology and treatment of recurrent UTI after renal transplant.

\begin{tabular}{|c|c|c|c|c|}
\hline$N$ & $\begin{array}{c}\text { 1st UTI } \\
97 \\
- \\
\end{array}$ & $\begin{array}{c}\text { 2nd UTI } \\
56 \\
57 \% \\
\end{array}$ & $\begin{array}{c}\text { 3ed UTI } \\
27 \\
27 \% \\
\end{array}$ & $\begin{array}{c}4 \text { th UTI } \\
14 \\
14 \% \\
\end{array}$ \\
\hline Days form transplant & $40.8 \pm 44.5$ & $70.1 \pm 45.4$ & $89.9 \pm 39.9$ & $124.2 \pm 44.5$ \\
\hline Asymptomatic UTI & $\begin{array}{c}58 \\
63.7 \%\end{array}$ & $\begin{array}{c}34 \\
60.7 \%\end{array}$ & $\begin{array}{c}13 \\
48.1 \%\end{array}$ & $\begin{array}{c}7 \\
50.0 \%\end{array}$ \\
\hline Simple UTI & $\begin{array}{c}14 \\
14.4 \%\end{array}$ & $\begin{array}{c}5 \\
8.9 \%\end{array}$ & $\begin{array}{c}5 \\
18.5 \%\end{array}$ & $\begin{array}{c}2 \\
14.3 \%\end{array}$ \\
\hline Complicated UTI & $\begin{array}{c}12 \\
12.4 \%\end{array}$ & $\begin{array}{c}8 \\
14.3 \%\end{array}$ & $\begin{array}{c}2 \\
7.4 \%\end{array}$ & $\begin{array}{c}4 \\
28.6 \%\end{array}$ \\
\hline Complicated with bacteremia & $\begin{array}{c}6 \\
6.2 \% \\
\end{array}$ & $\begin{array}{c}5 \\
8.9 \% \\
\end{array}$ & $\begin{array}{c}4 \\
14.8 \% \\
\end{array}$ & $\begin{array}{c}1 \\
7.1 \% \\
\end{array}$ \\
\hline Multidrug-resistant organism (MDRO) & $\begin{array}{c}41 \\
42.3 \% \\
\end{array}$ & $\begin{array}{c}28 \\
50.0 \% \\
\end{array}$ & $\begin{array}{c}17 \\
63.0 \% \\
\end{array}$ & $\begin{array}{c}8 \\
57.1 \% \\
\end{array}$ \\
\hline Not treated & $\begin{array}{c}13 \\
13.4 \%\end{array}$ & $\begin{array}{c}9 \\
16.1 \%\end{array}$ & $\begin{array}{c}2 \\
7.4 \%\end{array}$ & $\begin{array}{c}3 \\
21.4 \%\end{array}$ \\
\hline Treated out-patient & $\begin{array}{c}36 \\
37.1 \%\end{array}$ & $\begin{array}{c}29 \\
51.8 \%\end{array}$ & $\begin{array}{c}11 \\
40.7 \%\end{array}$ & $\begin{array}{c}6 \\
42.9 \%\end{array}$ \\
\hline Treated in-patient & $\begin{array}{c}48 \\
49.5 \%\end{array}$ & $\begin{array}{c}18 \\
32.1 \%\end{array}$ & $\begin{array}{c}14 \\
51.9 \%\end{array}$ & $\begin{array}{c}5 \\
35.7 \%\end{array}$ \\
\hline
\end{tabular}

(1) Routine stent removal: within 2 weeks after transplant for living donor kidney transplantation and in 2-4 weeks for deceased donor kidney transplantation

(2) Urgent stent removal: if a patient develops UTI, removal of the stent is sought once the infection is controlled

(3) Emergent stent removal: unstable patients with severe sepsis due to UTI or fungal infection [21]

In our study, when the urinary stent was removed after 21 days of transplantation, there was a trend towards a higher odds of developing UTIs although this trend was not statistically significant (OR 1.43, P; 0.259, CI: 0.76-2.66). Of note, when the stent was removed on urgent basis not related to UTIs, such as a migrated or a fallen stent, there were statistically less UTIs. Nonetheless, the number of recipients who had urgent early removal of their stent was too low to yield conclusive statements. Our group had previously suggested that studying "UTIs related to urinary stent" defined as UTIs while the ureteral stent is still in vivo and up to two weeks after its removal is a better indicator of the impact of the timing of stent removal than reviewing UTIs for a total duration of 3 or 6 months after transplantation [29]. Multiple other studies have examined the impact of stent removal at different intervals form renal transplantation including at 4 weeks [30], 3 weeks [31], 2 weeks [32], one week [33], or 5 days [34] after renal transplantation. These studies have shown that early removal of ureteric stents following kidney transplantation may potentially reduce the incidence of UTI without a significant increase of major urological complications. Adoption of an earlier stent removal protocol may be beneficial.

The antibiotics prophylaxis protocol at our center used to consist of a combination of Bactrim DD every other day for six months along with norfloxacin $400 \mathrm{mg}$ daily for the first 3 months. This protocol was based on the previous studies that evaluated the effects of dual prophylactic coverage with fluroquinolone and TMP/SXT versus TMP/SXT alone in post-kidney-transplant patients [35, 36]. This practice was modified in July 2018, and the current protocol consists of Bactrim SS for 6 months which is conjunctly used as prophylaxis for Pneumocystis carinii pneumonia [21, 37]. In this study, dual antibiotic prophylaxis (norfloxacin along 
Table 3: Predictors of first UTI after renal transplantation.

\begin{tabular}{|c|c|c|c|c|}
\hline & $P$ value & OR & 95 & $\mathrm{CI}$ \\
\hline Age $<=40$ years & \multicolumn{4}{|c|}{ Reference } \\
\hline$>40$ years & 0.012 & 2.176 & 1.187 & 3.986 \\
\hline Gender: male & \multicolumn{4}{|c|}{ Reference } \\
\hline Female & $<0.001$ & 5.008 & 2.74 & 9.156 \\
\hline No DM & \multicolumn{4}{|c|}{ Reference } \\
\hline DM type I & 0.551 & 0.719 & 0.243 & 2.128 \\
\hline DM type II & 0.053 & 1.948 & 0.99 & 3.833 \\
\hline Preemptive transplant & 0.28 & 1.871 & 0.6 & 5.834 \\
\hline Transplant abroad & $<0.001$ & 5.008 & 2.607 & 27.05 \\
\hline Living donor & \multicolumn{4}{|c|}{ Reference } \\
\hline Deceased donor & 0.394 & 0.714 & 0.329 & 1.55 \\
\hline Basiliximab & \multicolumn{4}{|c|}{ Reference } \\
\hline Thymoglobulin (ATG) & 0.476 & 1.274 & 0.655 & 2.477 \\
\hline Neurogenic bladder & 0.048 & 5.646 & 1.016 & 31.379 \\
\hline Vesicoureteral reflux & 0.375 & 2.419 & 0.344 & 17.012 \\
\hline Stent removed $<=21$ days & \multicolumn{4}{|c|}{ Reference } \\
\hline$>21$ days & 0.259 & 1.43 & 0.768 & 2.663 \\
\hline Rejection & 0.97 & 0.98 & 0.333 & 2.882 \\
\hline $\mathrm{BK}^{\dagger}$ & 0.656 & 0.757 & 0.222 & 2.581 \\
\hline Foley $>7$ days & 0.079 & 1.918 & 0.926 & 3.97 \\
\hline Bactrim $\mathrm{SS}^{\wedge}$ & \multicolumn{4}{|c|}{ Reference } \\
\hline Bactrim DS $+N^{*}$ & 0.138 & 0.584 & 0.287 & 1.189 \\
\hline
\end{tabular}

$\mathbf{\Delta}_{\text {Trimethoprim/sulfamethoxazole } 80 / 400 \mathrm{mg} \text { daily; }{ }^{*} \text { trimethoprim/sulfa- }}$ methoxazole, 160/800 mg every other day + nitrofurantoin $400 \mathrm{mg}$ daily. ${ }^{\dagger}$ Detected polyoma viremia $>50$ copies $/ \mathrm{ml}$.

with Bactrim DD) was not associated with the decreased risk of UTIs when compared to the standard prophylaxis with Bactrim SS daily.

The most common organisms in our study were Escherichia coli $51 \%$ and Klebsiella $18 \%$. MDROs were very common and constitute about $42 \%$ of the microorganisms on the first episode and $50 \%$ on the second episode of UTI. Such high rates have also been reported in other studies $[5,12,15,17,19,23]$.

UTIs may have little or no impact on the long-term outcome of the graft survival $[2,12]$. However, UTIs remain a leading cause of hospitalization after transplantation [3,9] and the hospitalization rate due to UTIs was $49 \%$ of the first UTIs and $32 \%$ of the first recurrence in our study. Such high rate of hospitalization is associated with significant cost and can add to the burden of the healthcare system.

The limitation of this study is the retrospective nature of the study at a single center.

\section{Conclusions}

UTIs and recurrence are common in the first 6 months after renal transplantation. Age $>40$, female gender, neurogenic bladder, and transplantation abroad are associated with the increased risk of UTIs and recurrence.

In-hospital treatment is frequently required, and MDROs are common causative organisms.

Dual antibiotic coverage (when compared to Bactrim SS alone) was not associated with the decreased risk of UTI.
A controlled trial will be required to depict the best timing of stent removal after kidney transplantation.

\section{Abbreviations \\ MDRO: Multidrug-resistant organism \\ Bactrim DS: Trimethoprim/sulfamethoxazole $160 / 800 \mathrm{mg}$ \\ Bactrim SS: Trimethoprim/sulfamethoxazole 80/400 mg \\ UTI: Urinary tract infection \\ VUR: $\quad$ Vesicoureteral reflux.}

\section{Data Availability}

The data used to support the findings of this study are included within the article.

\section{Conflicts of Interest}

The authors declare no conflicts of interest.

\section{Authors' Contributions}

Ziad Arabi and Khalefa Al Thiab made substantial contributions to conception and design, acquisition of data, analysis and interpretation of data, and drafting and revising of the manuscript. Lina Al Najjar, Marah Al Qahtani, Raghad Al Muhiteb, Rawan Al Hussain, Bashayer Al Qhatani, and Rayana Al Otaibi made substantial contributions to acquisition of data. Khalid Bin Saad, Wael Ohali, Abdulrahman Tamimi, Mohammed Tawhari, Mohammed Al Marastrani, Sami Kashkoosh, Ghalib Aboalsameh, and Abdulrahman Altheaby were involved in revising the manuscript.

\section{References}

[1] A. Shapouri Moghaddam, M. Arfaatabar, J. Tavakol Afshari, A. Shakerimoghaddam, Z. Mohammadzamani, and A. Khaledi, "Prevalence and antimicrobial resistance of bacterial uropathogens isolated from Iranian kidney transplant recipients: a systematic review and meta-analysis," Iranian Journal of Public Health, vol. 48, no. 12, pp. 21652176, 2019.

[2] S. Olenski, C. Scuderi, A. Choo et al., "Urinary tract infections in renal transplant recipients at a quaternary care centre in Australia," BMC Nephrology, vol. 20, no. 1, Article ID 479, 2019.

[3] L. F. C. Giordano, M. F. Lasmar, H. R. Vianna, L. F. Lasmar, and R. V. S. Palma, "Risk factors related to urinary tract infection in renal transplant recipients: 539," Transplantation, vol. 94, no. 10S, Article ID 849, 2012.

[4] M. V. N. L. R. Mohan, M. Neeraja, S. Sudhaharan, S. B. Raju, T. Gangadhar, and V. Lakshmi, "Risk factors for urinary tract infections in renal allograft recipients: experience of a tertiary care center in hyderabad, south India," Indian Journal of Nephrology, vol. 27, no. 5, pp. 372-376, 2017.

[5] D. G. K. Hooker, K. Foster, and A. Dodson, "Multi-drug resistant urinary tract infections following renal transplant: risk factors and patient outcomes," American Journal of Transplantation, vol. 17, no. 3, 2017.

[6] F. A. Shaheen, N. Basri, Z. Mohammed et al., "Experience of renal transplantation at the king fahd hospital, jeddah, Saudi 
Arabia," Saudi Journal of Kidney Disease and Transplantation, vol. 16, no. 4, pp. 562-572, 2005.

[7] M. Alkatheri, "Urinary tract infections in Saudi renal transplant recipients," Journal of Infectious Diseases and Immunity, vol. 5, no. 2, pp. 18-23, 2013.

[8] A. M. Alkatheri, A. M. Albekairy, S. Alharbi et al., "Investigation of the effectiveness of antibacterial prophylaxis in renal transplant recipients," The Journal of Infection in Developing Countries, vol. 8, no. 10, pp. 1244-1251, 2014.

[9] S. Greissman, A. Mattiazzi, M. Mendoza et al., "Antimicrobial resistance and recurrent bacterial urinary tract infections in hospitalized patients following kidney transplantation: a single-center experience," Transplant Infectious Disease: An Official Journal of the Transplantation Society, vol. 22, no. 4, Article ID e13337, 2020.

[10] J. D. Goldman and K. Julian, "Urinary tract infections in solid organ transplant recipients: guidelines from the American society of transplantation infectious diseases community of practice," Clinical Transplantation, vol. 33, no. 9, Article ID e13507, 2019.

[11] C. A. B. Santos and C. Daniel, Kidney Transplantation in Adults: Urinary Tract Infection in Kidney Transplant Recipients, Uptodate, Waltham, MA, USA, 2020, https://wwwuptodate-com.ezproxy.alfaisal.edu/contents/kidneytransplantation-in-adults-urinary-tract-infection-in-kidneytransplant-recipients? search=UTI\%20post $\% 20$ renal\% 20transplant\&source $=$ search result\&selectedTitle $=1 \sim 150 \&$ usage_type $=$ default $\&$ display_ rank $=1$.

[12] M. Papasotiriou, E. Savvidaki, P. Kalliakmani et al., "Predisposing factors to the development of urinary tract infections in renal transplant recipients and the impact on the long-term graft function," Renal Failure, vol. 33, no. 4, pp. 405-410, 2011.

[13] N. Sabé, I. Oriol, E. Melilli et al., "Antibiotic treatment versus no treatment for asymptomatic bacteriuria in kidney transplant recipients: a multicenter randomized trial," Open Forum Infectious Diseases, vol. 6, no. 6, Article ID ofz243, 2019.

[14] J. Coussement, A. Scemla, D. Abramowicz, E. V. Nagler, and A. C. Webster, "Antibiotics for asymptomatic bacteriuria in kidney transplant recipients," Cochrane Database of Systematic Reviews, vol. 2, no. 2, Article ID CD011357, 2018.

[15] J. E. Gołębiewska, A. Dębska-Ślizień, and B. Rutkowski, "Urinary tract infections during the first year after renal transplantation: one center's experience and a review of the literature," Clinical Transplantation, vol. 28, no. 11, pp. 1263-1270, 2014.

[16] K. O. Memikoğlu, K. Keven, S. Sengül, Z. Soypaçaci, S. Ertürk, and B. Erbay, "Urinary tract infections following renal transplantation: a single-center experience," Transplantation Proceedings, vol. 39, no. 10, pp. 3131-3134, 2007.

[17] P. Chuang, C. R. Parikh, and A. Langone, "Urinary tract infections after renal transplantation: a retrospective review at two US transplant centers," Clinical Transplantation, vol. 19, no. 2, pp. 230-235, 2005.

[18] K. Takai, J. Tollemar, H. E. Wilczek, and C. G. Groth, "Urinary tract infections following renal transplantation," Clinical Transplantation, vol. 12, no. 1, pp. 19-23, 1998.

[19] T. H. Sqalli, A. Laboudi, M. Arrayhani et al., "Urinary tract infections in renal allograft recipients from living related donors," Saudi journal of kidney diseases and transplantation: An Official Publication of the Saudi Center for Organ Transplantation, Saudi Arabia, vol. 19, no. 4, pp. 551-553, 2008.
[20] V. P. Alberts, M. M. Idu, D. A. Legemate, M. P. Laguna Pes, and R. C. Minnee, "Ureterovesical anastomotic techniques for kidney transplantation: a systematic review and meta-analysis," Transplant International, vol. 27, no. 6, pp. 593-605, 2014.

[21] Z. Arabi, A. Theaby, M. Farooqui, M. Abdalla, A. Hajeer, and K. Abdullah, "The National Guard Health Affairs guidelines for the medical management of renal transplant patients," Saudi Journal of Kidney Diseases and Transplantation, vol. 29, no. 6, pp. 1452-1469, 2018.

[22] M. P. Rodríguez Sánchez, D. C. Afanador Rubio, I. M. Luna et al., "Impact of complicated urinary tract infection on renal graft function," Transplantation Proceedings, vol. 52, no. 4, pp. 1173-1177, 2020.

[23] M. P. Freire, L. Martinho, C. V. Mendes et al., "Institutional protocol adherence in the incidence of recurrent urinary tract infection after kidney transplantation," Journal of Global Antimicrobial Resistance, vol. 23, pp. 352-358, 2020.

[24] N. Chacón-Mora, J. Pachón Díaz, and E. Cordero Matía, "Urinary tract infection in kidney transplant recipients," Enfermedades Infecciosas Y Microbiología Clínica, vol. 35, no. 4, pp. 255-259, 2017.

[25] M. Fiorentino, F. Pesce, A. Schena, S. Simone, G. Castellano, and L. Gesualdo, "Updates on urinary tract infections in kidney transplantation," Journal of Nephrology, vol. 32, no. 5, pp. 751-761, 2019.

[26] F. Friedersdorff, S. Weinberger, N. Biernath, H. Plage, H. Cash, and N. El-Bandar, "The ureter in the kidney transplant setting: ureteroneocystostomy surgical options, double-J stent considerations and management of related complications," Current Urology Reports, vol. 21, no. 1, Article ID 3, 2020.

[27] M. Ranganathan, M. Akbar, M. A. Ilham, R. Chavez, N. Kumar, and A. Asderakis, "Infective complications associated with ureteral stents in renal transplant recipients," Transplantation Proceedings, vol. 41, no. 1, pp. 162-164, 2009.

[28] I. J. Visser, J. P. T. van der Staaij, A. Muthusamy, M. Willicombe, J. A. Lafranca, and F. J. M. F. Dor, "Timing of ureteric stent removal and occurrence of urological complications after kidney transplantation: a systematic review and meta-analysis," Journal of Clinical Medicine, vol. 8, no. 5, Article ID 689, 2019.

[29] Z. Arabi, K. Al Thiab, A. Altheaby et al., "The impact of timing of stent removal on the incidence of UTI, recurrence, symptomatology, resistance, and hospitalization in renal transplant recipients," Journal of transplantation, vol. 2021, Article ID 3428260, 8 pages, 2021.

[30] A. Tavakoli, R. S. Surange, R. C. Pearson, N. R. Parrott, T. Augustine, and H. N. Riad, "Impact of stents on urological complications and health care expenditure in renal transplant recipients: results of a prospective, randomized clinical trial," The Journal of Urology, vol. 177, no. 6, pp. 2260-2264, 2007.

[31] L. Huang, X. Wang, Y. Ma et al., "A comparative study of 3week and 6-week duration of double-J stent placement in renal transplant recipients," Urologia Internationalis, vol. 89, no. 1, pp. 89-92, 2012.

[32] D. Yahav, H. Green, N. Eliakim-Raz, E. Mor, and S. Husain, "Early double J stent removal in renal transplant patients to prevent urinary tract infection-systematic review and metaanalysis of randomized controlled trials," European Journal of Clinical Microbiology \& Infectious Diseases, vol. 37, no. 4, pp. 773-778, 2018.

[33] S. Liu, G. Luo, B. Sun et al., "Early removal of double-J stents decreases urinary tract infections in living donor renal 
transplantation: a prospective, randomized clinical trial," Transplantation Proceedings, vol. 49, no. 2, pp. 297-302, 2017.

[34] P. Patel, I. Rebollo-Mesa, E. Ryan et al., "Prophylactic ureteric stents in renal transplant recipients: a multicenter randomized controlled trial of early versus late removal," American Journal of Transplantation, vol. 17, no. 8, pp. 2129-2138, 2017.

[35] F. Khorvash, M. Mortazavi, A. Hakamifard, and B. Ataei, "Comparison of the effect of co-trimoxazole and co-trimoxazole plus ciprofloxacin in urinary tract infection prophylaxis in kidney transplant patients," Advanced Biomedical Research, vol. 5, Article ID 108, 2016.

[36] D. Wojciechowski and S. Chandran, "Effect of ciprofloxacin combined with sulfamethoxazole-trimethoprim prophylaxis on the incidence of urinary tract infections after kidney transplantation," Transplantation, vol. 96, no. 4, pp. 400-405, 2013.

[37] N. E. Tolkoff-Rubin, A. B. Cosimi, P. S. Russell, and R. H. Rubin, "A controlled study of trimethoprim-sulfamethoxazole prophylaxis of urinary tract infection in renal transplant recipients," Clinical Infectious Diseases, vol. 4, no. 2, pp. 614-618, 1982. 